\title{
Trauma-Inspired Prosocial Leadership Development
}

\author{
Jenifer Wolf Williams, Ed.D. \\ Licensed Professional Counselor and Independent Researcher \\ Richardson, TX 75080 \\ Jenifer@JeniferWilliamsCounseling.com \\ University of La Verne, CA \\ Stuart Allen, Ph.D. \\ Associate Professor \\ Robert Morris University \\ Department of Organizational Leadership \\ Pittsburgh, PA \\ allens@rmu.edu
}

\begin{abstract}
Though trauma survivors sometimes emerge as leaders in prosocial causes related to their previous negative or traumatic experiences, little is known about this transition, and limited guidance is available for survivors who hope to make prosocial contributions. To understand what enables trauma-inspired prosocial leadership development, the transition narratives of seven trauma-inspired leaders who varied by global region, primary language, gender, ethnicity, religion, trauma type, and leadership area were analyzed. Using interpretative phenomenological analysis in an exploratory study, participants' transitional journeys were examined through analysis of their autobiographies. Critical findings included frequent references by all participants to perspective enlargement (reframing a problem or context) and resilience to the negative, apathetic, or retaliatory responses to the mission (possibly learned through resilience to trauma itself). This study explores posttraumatic leadership conceptually and makes suggestions for leadership development among trauma-inspired survivors.
\end{abstract}

\section{Introduction}

Leaders of prosocial change are sometimes propelled by traumatic personal experiences to lead other sufferers to wholeness, to prevent future tragedies similar to their own (Fazio, 2009; Frazier et al., 2012), or to make a similar positive contribution to society. An example is Sydney Rittenberg, a US citizen who was imprisoned for 16 years in years in China in solitary confinement. Bennis and Thomas (2007) describe Rittenberg as someone who "emerged stronger and surer than before" (p. 101) from this leadership crucible. Rittenberg went on to be a successful businessman and consultant to companies doing business in China (Rittenberg \& Bennett, 2001). Trauma-inspired prosocial leaders transform personal loss into a starting point for social good. 
Traumatic loss has been cited as the motivation behind the foundation of Mothers Against Drunk Driving, the Susan G. Komen Foundation, and numerous parent-led organizations (Frazier et al., 2012). Survivors have also organized successful efforts against trafficking and slavery (Cadet, 2011; Lloyd, 2012). Some trauma-inspired leaders rise from varying dark circumstances (e.g., torture, slavery, bereavement, and genocide) with a common thirst to transform their pain into a greater good. Literature specific to posttraumatic leadership is scarce (Frazier et al., 2012; McGovern, 2006), and scholarly practitioners have called for additional research (Fazio, 2009; McGovern, 2006). The aim of the current study was to understand how trauma-inspired prosocial leadership develops_-and ultimately_-how it can be developed in and by survivors.

\section{Background}

Posttraumatic Stress Disorder (PTSD) has occupied a noticeable role in the news media in recent years (e.g., Ansberry, 2014) with concern for veterans of various wars the US has engaged in. War is not the only circumstance that contributes to PTSD, with accidents, natural disasters (Andreason, 2010), crime (Allen \& Ortlepp, 2010), and torture (Punamäki, Qouta, \& Sarraj, 2010) being other examples of initiating events. PTSD is defined by the American Psychiatric Association's Diagnostic and Statistics Manual of Psychiatric Disorder (DSM-5, 2013) as a series of maladaptive responses to "actual or threatened death, serious injury, or sexual violence" (DSM-5, 2013, code 309.81). Exposure may consist of direct experience, personal witness, or learning that a close friend or family member experienced a traumatic event. Repeated or extreme exposure to related details in the course of one's work is also defined as trauma. Despite use of the term disorder, negative responses to trauma are sometimes described as normal responses to abnormal events. To be diagnosed with PTSD, an individual's response to such an event must include functionally significant intrusive recollection (so called flashbacks), avoidant or numbing behaviors, negative alterations in mood and cognition, and hyper-arousal (or hypervigilance), all with a duration of more than one month (DSM-5, 2013). PTSD has the potential to negatively impact an individual's life and work (Allen \& Ortlepp, 2010), through impairments such as,
"sleep disturbances ... sudden and unexpected panic ... persistent anxiety and feelings of intense alertness and vigilance ... unexpected and intrusive memories and associations to distressing events ... mood shifts that fluctuate by hours and days, particularly as characterized by sadness and anger ... awkwardness and hesitance in social relationships, even with family and close friends ... fatigue, weakness, somatic complaints (particularly gastrointestinal), and headaches ... difficulties paying attention and concentrating, resulting in poor memory and comprehension ... [and] decreased libido, low interest in pleasurable activities, and shifting (often diminished) appetite (Xenakis, 2014, p.40).

Following trauma, individuals go through the challenging process of recovery. Vasterling, Daly, and Friedman (2011) reviewed studies focused on recovery, noting that some may experience a "greater appreciation for life, sense of mastery" (p. 35), but most never fully recover. Reactions may be delayed, with PTSD developing months or years later. For many trauma survivors, especially where there are physical injuries (e.g., combat veterans), it may take years to adapt to the dual role of disability and psychological injury and develop the ability to live while still experiencing PTSD symptoms. 
Tedeschi and Calhoun (2004) describe posttraumatic growth (PTG) as "the experience of positive change occurs as a result of the struggle with highly challenging life crises" (p. 1). They propose that PTG is not a direct result of trauma, but instead evolves after the trauma through mitigating effects of personality characteristics, management of distressing emotions, support, disclosure, cognitive processing, and narrative development. They noted that individuals who experience PTG display a variety of growth areas, including changed priorities, improved relationships, increased appreciation for life, increased personal strength, spiritual development, and openness to new possibilities.

McGovern (2006) discusses examples of individuals who, after trauma, were compelled to seek social justice for others. This concept appears directly related to prosocial leadership. Lorenzi (2004) describes prosocial leadership as "a positive, effective influence, with constructive goals that serve the common good" (p.283). Trauma has the potential to create deeply held meaning, which provides trauma-inspired leaders a vision for their organization or cause (Yoeli \& Berkovich, 2010). Vaillant (1995) reports that altruism is one of multiple healthy means of adapting to the challenges of life. Victor Frankl's (1986) Man's Search for Meaning is a good example, as the author tells of his experience in the Auschwitz death camps and how finding meaning in his experience helped him survive. Frankl went on to positively impact the field of psychology and society through his personal experience.

Over the past decades, trauma theorists have moved toward a positive view of trauma response (Seligman, 2002). In spite of important negative consequences, researchers also acknowledge that resilience is common (Bonanno, 2004, 2005; Bonanno \& Mancini, 2008; Garmezy, 1985). Many trauma survivors report subsequent PTG as a major life change they experience as highly positive (Tedeschi \& Calhoun, 2004). Similar suggestions have been made by leadership development authors like Bennis and Thomas (2007), Dotlich, Noel, and Walker (2004), McCall, Lombardo, and Morrison (1988), and Thomas (2008) in relation to adverse life experience or life's hard times.

Hobfoll et al. (2007) proposed that service to others is essential for the development of healthy PTG. This assertion remains controversial, but many researchers agree that serving others can and does lead survivors to adjustment levels that exceed their pre-trauma functioning (Frazier et al., 2012; Park \& Fenster, 2004). In a controlled observation of 1281 university students, Frazier et al. (2012) found that higher levels of trauma experience (recent and lifetime) were associated with higher levels of prosocial behavior (short-term and long-term). Bennis and Thomas (2007), in their study of geeks and geezers (highly successful leaders from two generations), observed that these leaders came through adversity "in good psychological health, ready and able to tell others their tales" (p. 101). However, Bennis and Thomas also acknowledged that some are less resilient and "emerge confused and demoralized" (p. 101). Frazier et al. (2012) noted their findings suggest that negative experiences served as motivation for prosocial behavior, but that additional studies were needed to reveal the specific motivational processes involved.

Leadership development theories also provided foundational concepts for this study. Leadership theorists increasingly view personal experience as central to leadership development. Turner and Mavin (2008) asserted that adverse life events enable leadership, create a lasting 
impact, and propel individuals "to a different place" (p. 380). Yip and Wilson (2010) discussed the research on personal experience in development adding "As personal learning experiences, U.S. managers said midlife transitions and trauma - brought on, for example, by divorce or death in the family - taught them how to manage life and work" (pp. 80-81). Gardner, Avolio, Luthans, May, and Walumbwa (2005) proposed that personal histories are a starting point for the development of authentic leadership, and "key trigger events serve as catalysts for heightened levels of leader self-awareness" (p. 347). Bennis and Thomas (2007), Dotlich, Noel, and Walker (2004), McCall, Lombardo, and Morrison (1988), and Thomas (2008) specifically chronicle the role of hard times and tasks in leaders' development (e.g., loss of loved one, personal illness or injury).

To better understand the development of prosocial leadership among trauma survivors, this study focused on a sample of leaders who have shared their transition narratives in autobiographical form. Further insight into this transition holds potential for: a) interventions and training that support trauma-inspired leaders to master their experience and contribute through effective prosocial leadership; and b) structured prosocial leadership experiences that benefit survivors and those they serve.

\section{Methodology}

Narrative methodology is an established choice for investigations in which previous studies are limited and research questions are exploratory (Alvesson, 1996). It is also established as a means to give voice to members of oppressed groups (Apitzsch \& Siouti, 2007; Dickerson, 2011; Polkinghorne, 2007), making it suitable for participants whose trauma was inflicted by dominant others. The use of published narratives in the current study reduced the risk of harm to participants (e.g., revisiting the trauma) and provided a rich multicultural data source. Published accounts of posttraumatic leadership development were readily available (Almond, 2012; Rodriguez, 2012; Taylor, 2008), yet no evidence was found these data sources had ever been analyzed.

Biographical narrative analysis is recognized as an important epistemological method within a variety of social science disciplines, particularly for investigating complex multicultural phenomena (Apitzsch \& Siouti, 2007). Initiated by sociologists Thomas and Znaniecki (1918/1958) in the early twentieth century, the method declined in use during the positivist period but garnered renewed interest beginning in the 1970's (Apitzsch \& Siouti, 2007). Shamir, DayanHoresh, and Adler (2005) turned to autobiographical analysis for their in-depth exploration of leadership development. The researchers asserted that leaders' autobiographical narratives reflect both leadership identity and self-identity at the time of writing, "even when (leaders) are not being presented with these questions by an external source and even when they do not address them in an explicit manner" (Shamir et al., 2005, p. 18).

Population and Sampling. For the purpose of sampling, trauma-inspired leaders were identified as those who meet three inclusive criteria: trauma history (Criterion A of the DSM 5, $A P A, 2013$ ), prosocial leadership (Lorenzi, 2004), and a connection (obvious or stated by the survivor) between the two. Participant selection goals included richness of narrative data and diversity of survivors' demographics, trauma types, and leadership areas. To reduce subjectivity 
and broaden possible sources for inclusion, recommendations were requested from numerous resources (e.g., librarians, mental health care professionals, and leadership and psychology professors). Seven autobiographies (Table 1) of trauma-inspired leaders were selected providing detailed accounts of their journeys and representing a diverse sample with regard to leader background, trauma type, and leadership area (see table 1).

Table 1

Range of Prosocial Leaders Included

\begin{tabular}{|c|c|c|c|c|c|c|}
\hline Leader & $\begin{array}{l}\text { Pub. } \\
\text { year }\end{array}$ & $\begin{array}{l}\text { Culture of } \\
\text { origin }\end{array}$ & Gender & $\begin{array}{l}\text { Trauma } \\
\text { type }\end{array}$ & $\begin{array}{l}\text { Initial } \\
\text { leadership } \\
\text { focus }\end{array}$ & $\begin{array}{l}\text { Initial leadership } \\
\text { location }\end{array}$ \\
\hline rivuzumugabe & 2010 & $\begin{array}{l}\text { Rwandan } \\
\text { Tutsi }\end{array}$ & M & Genocide & $\begin{array}{l}\text { Encourage \& } \\
\text { inspire } \\
\text { orphans }\end{array}$ & Rwanda \\
\hline Brinker & 2011 & U.S. Midwest & $\mathrm{F}$ & $\begin{array}{l}\text { Loss to } \\
\text { cancer }\end{array}$ & $\begin{array}{l}\text { Eradicate } \\
\text { breast cancer }\end{array}$ & Dallas, TX \\
\hline Menchu & $\begin{array}{c}1987 \\
\& \\
2010\end{array}$ & $\begin{array}{l}\text { Quiche } \\
\text { (Guatemalan } \\
\text { indigenous) }\end{array}$ & $\mathrm{F}$ & Genocide & $\begin{array}{l}\text { Peace for } \\
\text { indigenous }\end{array}$ & Rural Guatemala \\
\hline Lloyd & 2013 & British & $\mathrm{F}$ & $\begin{array}{l}\text { Sexual } \\
\text { exploitati } \\
\text { on }\end{array}$ & $\begin{array}{l}\text { Rescue \& } \\
\text { nurture } \\
\text { sexually } \\
\text { exploited } \\
\text { girls }\end{array}$ & New York City \\
\hline Tenberken & 2003 & German & $\mathrm{F}$ & $\begin{array}{l}\text { Loss of } \\
\text { vision }\end{array}$ & $\begin{array}{l}\text { Teach blind } \\
\text { children }\end{array}$ & Tibet \\
\hline Cadet & 2011 & Haitian & M & $\begin{array}{l}\text { Child } \\
\text { slavery }\end{array}$ & $\begin{array}{l}\text { Eradicate } \\
\text { child slavery }\end{array}$ & Haiti \\
\hline Rodriguez & 1995 & U.S. Latino & M & $\begin{array}{l}\text { Street } \\
\text { violence }\end{array}$ & $\begin{array}{l}\text { Unite } \\
\text { communities }\end{array}$ & Los Angeles \\
\hline
\end{tabular}

\section{Procedure and Data Analysis}

Holistic analysis. Using the principles of Interpretative Phenomenological Analysis (Smith, Flowers, \& Larkin, 2012), individual narratives were analyzed holistically, followed with holistic and thematic cross-narrative analyses. Holistic analysis included reading and rereading, recording initial impressions, and separately identifying and recording areas of potential researcher bias. Each summary was deconstructed by topic (e.g., awakening of the need for justice) and a cross-narrative comparison was conducted, identifying commonalities among the leaders' reported experiences.

The holistic interpretive process began with reading and summarizing each narrative to provide condensed descriptions of reported transition experiences. Based on these summaries, 
interpretations were developed for each survivor's apparent overall message about factors important to the transition. Areas of potential researcher bias were recorded, including researcher demographics (e.g., female), researcher experience (e.g., trauma counselling), and subjective responses to the narratives. The seven individual interpretations were then deconstructed according to topic, allowing a comparison of similarities and differences among the transition narratives, and the identification of common themes among the leaders' reported experiences.

Thematic analysis. Thematic analysis began with in-depth reviews of the primary data. Emergent broad themes were identified within each narrative and all narrative segments that demonstrated those themes were recorded. Next, all identified primary data were uploaded into the web based Dedoose analysis system (Lieber, 2011), coded, and themed. Theme frequencies were tracked within and across narratives and were an important but not exclusive factor in determining the relative importance of each theme. Characteristics identified as critical by frequency were compared to those identified during holistic analysis, as well as to the findings of previous researchers in a multi-layered iterative approach.

Validity and reliability. Validity and reliability of narrative research rests on detailed observation, comparison of multiple methods, peer review, transparency, and rich description (Glesne, 2010; Carcary, 2009). In the current study, narratives were reviewed multiple times over several weeks, and multiple analytical methods were incorporated. The first author detailed analytical processes and personal biases in writing, which the second author thoroughly reviewed, requesting clarifications and suggesting alternate interpretations. Use of raw data also adds to validity of narrative research (Polkinghorne, 2007), and in the current study, all primary data is publicly available and referenced.

\section{Results}

The narratives confirmed the phenomenon of trauma-inspired prosocial leadership through clearly depicted examples. Each leader's experience was unique in its trauma type, cultural context, prosocial goals, and personal characteristics. Yet commonalities emerged among the leaders' reported motivations, actions, barriers, and cognitions.

Holistic Results. Characteristics identified through cross narrative holistic analysis are listed below. Neither their frequency nor their importance was measured by the holistic process, and their order here is solely for ease of comparison to thematic results.

1. To understand target problems, the leader reflected on larger societal issues.

2. The leader developed creative, positive responses to leadership barriers.

3. The leader sought education or training for self or for other potential leaders.

4. The leader acknowledged ongoing symptoms of distress.

5. The leader expressed or displayed the need for a period of personal healing and recovery.

6. The leader focused on help or encouragement from others.

7. The leader expressed or displayed empathy with the target group.

8. The leader expressed a sense of obligation toward an identified group.

9. The leader enabled collaborative connections among others.

10. The leader expressed or displayed a need for justice. 
11. The leader described the impact of religious faith (positive or negative).

Thematic Results. Identified broad theme categories included motivation for leadership, leadership actions, barriers to leadership, contribution of others, leader missteps, leader self-care, and leaders' concurrent faith journeys. Specific emergent themes within each category can be seen in Table 2, and examples of each are detailed in Table 3.

Table 2

Overall Frequencies

\begin{tabular}{|c|c|c|c|c|c|c|c|}
\hline Leader & 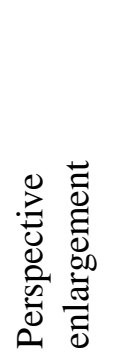 & 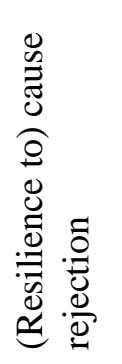 & 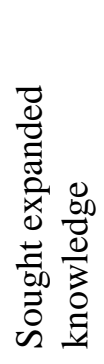 & 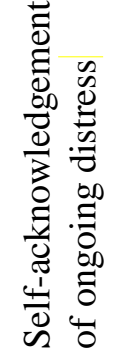 & 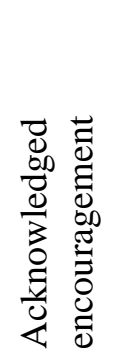 & 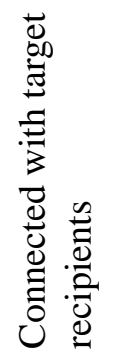 & 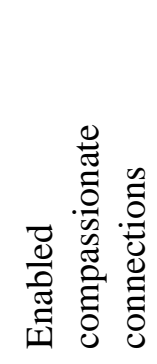 \\
\hline Tenberken & 11 & 28 & 18 & 2 & 9 & 7 & \\
\hline Menchu & 31 & 26 & 25 & 3 & 3 & 13 & 18 \\
\hline Lloyd & 9 & 7 & 9 & 11 & 11 & 16 & 12 \\
\hline Brinker & 17 & 5 & 2 & 6 & 2 & & \\
\hline Rodriguez & 18 & 10 & 13 & 12 & 10 & 5 & 4 \\
\hline Cadet & 17 & 13 & 9 & 23 & 14 & 17 & 21 \\
\hline Irivuzumugabe & 10 & & & 12 & 18 & 7 & 9 \\
\hline Totals & 113 & 89 & 76 & 69 & 67 & 65 & 64 \\
\hline
\end{tabular}


Table 3

Example quotes for frequently cited themes

\begin{tabular}{ll}
\hline Theme & Description \\
\hline Perspective & Considered how to \\
enlargement & reframe problem to \\
& $\begin{array}{l}\text { expand a solution or carry } \\
\text { to another level }\end{array}$
\end{tabular}
Example Quote

"There was something about the way Chente and the others made sense; the way they made dead things come alive - how they took what seemed obvious and proved the direct opposite. The words were a fascinating revelation for me. Another culture. I had never experienced anything like it. Here all perceptions were challenged. Here knowledge, this elusive dove which had never before found a landing near my grasp, could be gently held - where it would not fly away" (Rodriguez, 1995, p. 157).

(Resilience to) cause rejection

Apathy, negativity, or retaliation from target population or public

Sought expanded knowledge

Selfacknowledgement of ongoing distress

Acknowledged encouragement

Connected with target recipients

Enabled compassionate connections
Worked to understand problem or strategy from new perspectives and in greater depth

The leader described ongoing negative effects of the trauma event.

Acknowledged others' attempts to offer comfort or motivation

Made efforts to connect with those suffering from target trauma

United others for mutual support or support of target group
"I'm sobbing on the three-way with Cait and Mishi, crying from frustration, from anger, from disappointment that yet again we've failed to pass the bill and that yet again I have to tell the girls that the folks in power have chosen not to listen to their testimonies of abuse and violence." (Lloyd, 2013, p. 249).

"I learned a lot from my mother but I also learned a lot from other people, especially when I had the opportunity of talking to women who aren't from our country" (Menchu, 2010, p. 260).

"I have suffered through many night terrors. I've relived the horrifying chase of the devils close to my heels. Some nights I've dreamed of my own death. Other dreams bring the lifeless faces of my family before my eyes, covered in decay. I've been shaken out of such terrors to the smell of fresh blood in my room" (Irivuzumugabe, 2010, p. 146).

“They've been my family, the community where I've been able to hide and heal, at least enough to keep moving forward. On a small airbase in Germany they've accomplished a miracle. They've loved me back to life" (Lloyd, 2012, p. 228).

"I did my best to work with the families of these children. I told them the story of my own childhood and gave them extra food and blankets, explaining always that the children staying with them were sent by God and should be loved and fed like their own children. Before long, these eight girls were calling me 'Pappy Jean-Robert' with the biggest smiles on their faces" (Cadet, 2011, p. 10).

"When Mugabo was in the orphanage, I was working most of the time. He felt misplaced and abandoned, like he was waiting to die. Today he comes with me to visit the orphans, because he knows how the presence of another human being mysteriously strengthens them to keep trying" (Irivuzumugabe, 2009, p. 99). 
The most frequently cited transition characteristic across narratives and across theme categories was the leader action perspective enlargement (113 identified excerpts), defined as the leader's reframing of a problem to expand solution alternatives (often by deciphering larger societal issues behind target problems). At key points in their journeys, each leader charted a new path by stepping back from a problematic situation to reconsider from a larger view. Within this context, the leaders often sought new relationships with individuals from diverse backgrounds. They struggled to learn from life changes, and sometimes they instigated life changes in order to learn and grow. This tendency to seek overarching meanings and root causes enabled them to reframe barriers and open doors.

The second most commonly cited element across narratives was the leadership barrier cause rejection (89 identified excerpts), defined as negative, apathetic, or retaliatory responses to the mission by the recipient or broader population. Its strong presence within the context of effective leadership and successful missions implies the leaders maintained sufficient resilience to cause rejection to facilitate success in the face of challenges. Accounts of resilience to cause rejection varied from disregarding those who doubted the leader's mission to accepting continued risk of death.

The leadership action sought expanded knowledge (76 identified excerpts) was defined as a leader's purposeful effort to gain understanding of a problem or strategy. This leadership action sometimes culminated in perspective enlargement, but was differentiated as an initial step that may or may not have resulted in the leader's changing view.

The most frequently identified act of leader self-care was the self-acknowledgement of ongoing distress (69 identified excerpts). This concept ranked fourth in frequency overall and was reported or implied in varying degrees by all seven leaders. The counterintuitive juxtaposition of effective leadership and emotional distress supports previous findings connecting PTG to acknowledgement of posttraumatic distress symptoms (Dekel, Solomon, \& Ein-Dor, 2012).

The leadership self-care component acknowledged encouragement (from others) was defined as the leader's attention to an offer of comfort or motivation from another person. It accounted for 67 identified excerpts across narratives, making it the fifth most frequently cited element. This self-care action may be linked to the previous one in that acknowledgement of distress is a component of a survivor's ability to accept encouragement for related distress.

The leadership action connected with target recipients referred to leaders' personal and active identification with members of the target recipient group. This action sometimes involved leaders' sharing personal trauma and recovery histories to encourage new survivors. Additional examples included leaders' self-statements of compassion, or leader incorporations of unique understandings of recipients. The sixth most frequently identified element, it accounted for 65 excerpts across narratives.

The leadership action enabled compassionate connections among others was defined as uniting others with, or in support of, the target recipient group. This was the seventh most frequently cited element and accounted for 64 identified excerpts across the narratives. Within 
these excerpts, leaders identified strengths and resources of compassionate individuals or groups and matched them to needs of the target population.

Comparison of Holistic and Thematic Results. The separately derived holistic and thematic results enabled comparison between two data sources. Holistic analysis findings supported all seven of the thematic analysis findings listed above, as well as less frequently cited characteristics such as leadership motivation and leaders' religious faith.

\section{Discussion and Implications}

This study examined the concept of trauma-inspired prosocial leadership and described a lens through which to view it. Although exploratory in nature, the findings were consistent across a highly diverse set of trauma-inspired prosocial leaders and supported previous studies in multiple fields. Overall, the narratives directly supported observations that trauma survivors can experience positive changes as a result of their negative experiences (Bonanno, 2004, 2005; Bonanno \& Mancini, 2008; Tedeschi \& Calhoun, 2004) and that trauma experiences are associated with increased prosocial action (Frazier et al., 2012).

Perspective enlargement observations are consistent with transformative learning theory (Mezirow, 1991, 1994, 2000, 2003), which posits that the most significant adult learning comes in the form of powerful, multi-dimensional shifts in an individual's foundational premises about life, self, relationships, and awareness. Such shifts initiate a "disorienting dilemma" (Mezirow, 1994, p. 223) that disrupts deeply lodged assumptions by surfacing their incompatibilities with newly discovered realities. When the individual responds with critical reflection, the result is a clearer, more encompassing conceptual framework that leaves the individual open to possibilities beyond his or her previous imagination. Bennis and Thomas (2007) describe "seeing the world in a new light" (p. 106) as a result of a leadership crucible, while Dotlich et al. (2004) describe gaining perspective as an intentional step that developing leaders can take to overcome and learn from adversity.

In the current study, leadership actions tended to follow the leaders' broadening perspectives, and most began their journeys among individuals in their immediate context. As the leaders' perspectives grew, they carried their attention to ever broader recipient populations. This pattern of influence expansion may be similar to other prosocial leaders or to other leaders in general. In other words, a leader's expansion of influence seems commensurate with the expansion of his or her perspective. With regard to trauma-inspired leadership, it may be that the capacity to continually expand one's perspective is enhanced through the trauma experience itself. Trauma disrupts a survivor's worldview and requires the construction of new understandings. It appears this enhanced capacity provides an important resource for survivors who also wish to effect social change.

To some extent, this finding seems to contradict that of Park and Fenster (2004) who observed that worldview shift (similar to perspective enlargement) did not predict college students' stress related growth. The researchers acknowledged the unexpected nature of their finding and speculated that this may have resulted because the types of stress events participants reported were not severe enough to disrupt worldviews. If this speculation is accurate, the current 
findings suggest that the severity of the stressor increases the likelihood a worldview shift and PTG will occur. However, as noted by Bennis and Thomas (2007) and others, not everyone grows a result of trauma or adversity.

Leaders' frequent references to resilience to cause rejection supported previous findings that trauma survivors can and do experience posttraumatic changes which they view as highly positive (Bonanno, 2004, 2005; Bonanno \& Mancini, 2008; Tedeschi \& Calhoun, 2004). It may be that trauma-inspired leaders develop resilience long before their leadership journeys begin. Having been deliberately harmed by others, or having experienced the sense of being rejected by a force larger than themselves, survivors may become inoculated to additional rejections or negativity. They understand that negative experiences are not necessarily the end, and they navigate the inevitable setbacks of leadership. Thomas (2008) suggests that leaders' resilience, as a facet of adaptive capacity, is not always a trait, but can instead be developed - a learned, practiced routine or process. Such resilience may be a lesson of the trauma experience.

The concurrence of posttraumatic distress with trauma-inspired prosocial leadership is consistent with previous observations that posttraumatic dysfunction and growth are not mutually exclusive, but in fact, often coexist (Tedeschi \& Calhoun, 2004). Dekel et al. (2012), in a longitudinal study of Israeli former prisoners of war, found higher reported PTG trajectories among survivors with initial PTSD than among those without. The authors concluded that "growth is facilitated and maintained by endorsement rather than absence of PTSD" (Dekel et al., 2012 , p. 94). Leaders in the current study demonstrated willingness to acknowledge their symptoms and to move ahead with their lives in full recognition of concurrent distress.

Frazier et al. (2012) also observed a significant relationship between trauma-related distress and prosocial behavior, and an even more strongly positive relationship between prosocial behavior and measured aspects of wellbeing, especially positive affect and perceived meaning. The authors posited that while distress motivates prosocial behaviors, prosocial behaviors increase wellbeing. These observations may explain the high functioning of the seven participants, even in the presence of continued distress. In addition to altruism, a concept similar to prosocial behavior, other healthy, mature adaptive mechanisms to life challenges mentioned by Vaillant (1995) include sublimation, humor, anticipation, and suppression, many of which involve channeling potentially negative desires, reactions, and thoughts into positive means.

Limitations. The goal of this exploratory study was depth and applicability, rather than generalizability, and further study is needed before transferring findings to other trauma-inspired (or adversity-inspired) leaders. Despite attempts at broad inclusion, narrative selection involved chance and was subjective. Leaders without published narratives were not considered for inclusion, and it is likely participants differed in important ways from leaders whose narratives are not publicly available. Editorial influence on author intentions was also a possible weakness, as was the absence of nonverbal interaction between researcher and participants. Consistent with Interpretative Phenomenological Analysis, this study's aim was not to analyze the leadership transitions historically, but to understand those transitions from the leaders' own perspectives. 
Implications for Future Research. This study suggests the observed characteristics are applicable to leadership development among trauma survivors, and perhaps among leaders in general. As a next step, interviews of trauma-inspired prosocial leaders would allow a comparison of findings obtained through differing methodologies. Interviews would also avoid the distortions that might have occurred through publication editing. Additionally, the identified critical factors could be measured among a larger sample, allowing researchers to consider whether results might be generalized to the larger trauma survivor population or to leaders in general (e.g., veterans, first responders). Conversely, a more focused study could reveal transition characteristics specific to populations of clinical interest, such as medical trauma survivors or genocide and war trauma survivors. A narrower study focus might also be specific to culture, gender, or leadership areas. A study that explores the role of trauma in successful leaders' development among a broad sample might indicate whether trauma is a frequent factor in leadership development generally. Based upon writings such as those of Bennis and Thomas (2007), it seems likely that trauma has a broader role as a crucible than generally acknowledged. There is also potential for research focused upon therapeutic interventions that could be developed from the findings of this study, as detailed in the next section.

Implications for Practice. By exploring trauma-inspired leadership as a theoretical concept, this study lends support to the human rights applications McGovern (2006) advocated in her call to view trauma survivors as capable leaders rather than passive victims. It also supports the growth consultancy movement Fazio (2009) established for survivors of loss and adversity, as well as the Kanthari program (Kanthari, 2012), and the survivor-leader component of Girls Educational Mentoring Services (Lloyd, 2012).

The findings provide direction for trauma survivors who desire to move toward prosocial leadership, with broader potential applications to leadership development. For example, interventions and training may be developed or adapted that support trauma-inspired leaders to master their experience and contribute more effectively through prosocial leadership. Both Dotlich et al. (2004) and Thomas (2008) advocate in the leadership development literature for the intentional reflection on leadership crucibles or passages to maximize learning. Similar concepts might apply with trauma-survivors beyond conventional therapy in terms of training to develop the characteristics noted in the findings of this study (e.g., resilience). As Hobfoll et al. (2007) suggested, service to others or a greater social cause may be instrumental to recovery. For example, the prominence of perspective enlargement in the narratives suggests potential benefit from its development among survivors, and practitioners may want to consider adapting extant models of leadership development based on transformational learning principles (Debebe, 2011; Hodge, Magolda, \& Haynes, 2009; Kroth \& Boverie, 2009). Debebe (2011) described a framework through which trainers can promote transformational change among potential leaders based on individual experiences and worldviews. In addition, previous researchers have identified methods for increasing resilience (Gilham et al., 2007), and resilience training specific to leadership has already been implemented in the U.S. Army (Cornum, Matthews, \& Seligman, 2011). Trauma practitioners may want to consider adapting extant research based resilience programs to address resilience among survivors who wish to develop effective prosocial skills.

Involvement in structured prosocial leadership experiences also holds potential as a therapeutic intervention. The common co-occurrence of posttraumatic distress symptoms with 
effective prosocial leadership should also be shared with survivors. In fact, many of the findings listed under holistic analysis and in Tables 2 and 3 describe actions (e.g., "the leader sought education or training for self or for other potential leaders") which provide models of recovery that could support training or interventions. For example, trauma survivors might benefit from reading biographies or summarized biographies that highlight the actions taken by leaders. Recognition that distress is a common response to trauma and not indicative of reduced worth, or even reduced efficacy, may allow survivors to acknowledge symptoms and simultaneously move forward into prosocial action or leadership. Rather than wait for complete symptom eradication, survivors can be assured of their potential for valuable societal contributions even as they recover. Meanwhile, involvement in prosocial work might also aid their recovery. Similarly, awareness of trauma's positive potential might guide leadership development practitioners to better understand the value these events can contribute toward leadership development, especially among such high incident populations as war veterans and refugees.

\section{Conclusion}

Overall, this study has exciting and hopeful implications for trauma survivors and those who support them. It confirms that effective, prosocial action is a possible response to life's bitterest circumstances, and it uncovers the paths some have taken to make such response a reality. The study provides support to assist survivors in understanding prosocial leadership development and suggests additional research for defining and refining those steps that could take survivors - and their target recipients - from pain to purpose.

\section{References}

Allen, S.A., \& Ortlepp, K. (2000). An investigation of the relationship between job-induced posttraumatic stress, work-based social support and three organizational variables. South African Journal of Industrial Psychology, 26(1), 1-5.

Almond, K. (2012, September 20). And the top $10 \mathrm{CNN}$ heroes of 2012 are... CNN.com. Retrieved August 9, 2013 from http://www.cnn.com/2012/09/20/world/cnnheroes-top10

Alvesson, M. (1996). Leadership studies: From procedure and abstraction to reflexivity and situation. The Leadership Quarterly, 7(4), 455-485.

American Psychiatric Association Committee on Nomenclature and Statistics (2013). Diagnostic and Statistical Manual of Mental Disorders (5th ed.). Washington, DC: American Psychiatric Association.

Andreasen, N. C. (2010). Posttraumatic stress disorder: A history and a critique. Annals of the New York Academy of Sciences, 1208(1), 67-71.

Ansberry, C. (2014, Nov 29). Delayed reaction: Rising numbers of veterans seek help decades after war. Wall Street Journal, A1. 
Apitzsch, U., \& Siouti, I. (2007). Biographical analysis as an interdisciplinary research: perspective in the field of migration studies. Research Integration, Heslington, UK: University of York.

Bennis, W. G., and Thomas, R. J. (2007). Leading for a lifetime: How defining moments shape the leaders of today and tomorrow. Boston, MA: Harvard Business School Press.

Bonanno, G. A. (2004). Loss, trauma, and human resilience: Have we underestimated the human capacity to thrive after extremely aversive events? American Psychologist, 59(1), 20-28.

Bonanno, G. A. (2005). Resilience in the face of potential trauma. Current Directions in Psychological Science, 14(3), 135-138.

Bonanno, G. A., \& Mancini, A. D. (2008). The human capacity to thrive in the face of potential trauma. Pediatrics, 121(2), 369-375.

Brinker, N. (2011) Promise me: How a sister's love launched the global movement to end breast cancer. New York, NY: Random House.

Cadet, J. R. (2011) My stone of hope: From Haitian slave child to abolitionist. Houston, TX: University of Houston Press.

Carcary, M. (2009). The research audit trial: Enhancing trustworthiness in qualitative inquiry. Electronic Journal of Business Research Methods, 7(1), 11-23.

Cornum, R., Matthews, M., \& Seligman, M. (2011). Comprehensive soldier fitness: building resilience in a challenging institutional context. American Psychologist, 66(1), 4-9.

Debebe, G. (2011). Creating a safe environment for women's leadership transformation. Journal of Management Education, 35(5), 679-712.

Dekel, S., Ein-Dor, T., \& Solomon, Z. (2012). Posttraumatic growth and posttraumatic distress: A longitudinal study. Psychological Trauma: Theory, Research, Practice, and Policy, 4(1), 94-101.

Dickerson, A. G. (2011). Healing and posttraumatic growth in African American survivors of domestic violence: An exploration of women's narratives (Doctoral dissertation). Available at ProQuest Digital Dissertations and Theses. (918994618)

Dotlich, D. L. Noel, J. L. \& Walker, N. (2004). Leadership passages: The personal and professional transitions that make or break a leader. San Francisco: CA: John Wiley \& Sons, Inc.

Fazio, R. (2009). Growth consulting: practical methods of facilitating growth through loss and adversity. Journal of Clinical Psychology, 65(5), 532-543. 
Frazier, P., Greer, C., Gabrielsen, S., Tennen, H., Tomich, P., \& Park, C. (2012). The relations between trauma exposure and prosocial behavior. Psychological Trauma: Theory, Research, Practice, and Policy, 5(3), 286-294.

Frankl, V. (1984). Man's search for meaning: An introduction to logotherapy (3rd ed.). New York, NY: Touchstone.

Garmezy, N. (1985). Stress-resistant children: The search for protective factors. In A. Davids (Ed.), Recent research in developmental psychopathology (pp. 213-233). Elmsford, NY: Pergamon Press.

Gardner, W. L., Avolio, B. J., Luthans, F., May, D. R., \& Walumbwa, F. (2005). "Can you see the real me?" A self-based model of authentic leader and follower development. Leadership Quarterly, 16(3), 343-372.

Gilham, J., Reivich, K., Freres, D., Chaplin, T., Shatte', A., Samuels, B., Elkon, A., Litzinger, S., Lascher, M., Gallop, R., \& Seligman, M. (2007). School-based prevention of depressive symptoms: A randomized controlled study of the effectiveness and specificity of the Penn Resiliency Program. Journal of Consulting and Clinical Psychology, 75(1), 9-19

Glesne, C. (2011). Becoming qualitative researchers: An introduction (4 ${ }^{\text {th }}$ ed.). Boston, MA: Pearson.

Hobfoll, S., Hall, B., Canetti-Nisim, D., Galea, S., Johnson, R., \& Palmieri, P. (2007). Refining our understanding of traumatic growth in the face of terrorism: Moving from meaning cognitions to doing what is meaningful. Applied Psychology: An International Review, 56(3), 345-366.

Hodge, D. C., Magolda, M. B., \& Haynes, C. A. (2009). Engaged learning: Enabling selfauthorship and effective practice. Liberal Education, 95(4), 16-23.

Irivuzumugabe, E. (2009). My father maker of the trees: How I survived the Rwandan genocide. Grand Rapids, MI: Baker Books.

Kanthari (2012). Kanthari.org. Retrieved August 9, 2013, from http://www.kanthari.org/

Kroth, M., \& Boverie, P. (2009). Using the discovering model to facilitate transformational learning and career development. Journal of Adult Education, 38(1), 43-47.

Lieber, E. (2011). Dedoose [online data analysis software]. Dedoose.com. Retrieved August 9, 2013, from http://www.dedoose.com/

Lloyd, R. (2012). Girls like us: Fighting for a world where girls are not for sale. New York, NY: Harper Collins. 
Lorenzi, P. (2004). Managing for the common good: Prosocial leadership. Organizational Dynamics, 33(3), 282-291.

McCall, M. W, Lombardo, M. M, and Morrison, A. M. (1988). The lessons of experience: How successful executives develop on the job. Third Avenue, NY: Lexington Books.

McGovern, T. (2006). Models of resistance: "Victims" lead. Health and Human Rights, 9(2), 234255.

Menchu, R. (1987/2010). I, Rigoberta Menchu. Brooklyn, NY: Verso.

Mezirow, J. (1991). Transformative dimensions of adult learning. San Francisco, CA: JosseyBass.

Mezirow, J. (1994). Understanding transformation theory. Adult Education Quarterly, 44(4), 22244.

Mezirow, J. (2000). Learning to think like an adult: Core concepts of transformation theory. In J.

Mezirow \& Associates (Eds.), Learning as transformation: Critical perspectives on a theory in progress (pp. 3-33). San Francisco, CA: Jossey-Bass.

Mezirow, J. (2003). Transformative learning as discourse. Journal of Transformative Education; $1(1), 58-63$.

Park, C., \& Fenster, J. (2004). Stress-related growth: Predictors of occurrence and correlates with psychological adjustment. Journal of Social and Clinical Psychology, 23(2), 195-215.

Polkinghorne, D. E. (2007). Validity issues in narrative research. Qualitative Inquiry, 13(4), 471486).

Punamäki, R., Qouta, S. R., \& Sarraj, E. E. (2010). Nature of torture, PTSD, and somatic symptoms among political ex-prisoners. Journal Of Traumatic Stress, 23(4), 532-536. doi: $10.1002 /$ jts. 20541

Rittenberg, S., \& Bennett, A. (2001). The man who stayed behind. Durham, NC: Duke University Press.

Rodriguez, L. J. (1995). Always running: Gang days in L.A. New York, NY: Touchstone.

Rodriguez, L. J. (2012, June 12). Meet Luis J. Rodriguez. Open Road Media. Retrieved August 9, 2013, from https://www.youtube.com/watch?v=W6OHXMcPv7k

Seligman, M. E. P. (2002). Authentic happiness: Using the new positive psychology to realize your potential for lasting fulfillment. New York, NY: Free Press. 
Shamir, B., Dayan-Horesh, H., \& Adler, D. (2005). Leading by biography: Towards a life-story approach to the study of leadership. Leadership, 1(1), 13-29.

Smith, J.A., Flowers, P., \& Larkin, M. (2012). Interpretative phenomenological analysis: Theory, method, and research. Los Angeles, CA: Sage.

Taylor, J. B. (2008, March). My stroke of insight. TEDtalks.com. Retrieved August 9, 2013 from http://www.ted.com/talks/jill_bolte_taylor_s_powerful_stroke_of_insight.html

Tedeschi, R., \& Calhoun, L. G. (2004). Posttraumatic growth: Conceptual foundations and empirical evidence. Psychological Inquiry, 15(1), 1-18.

Tenberken, S. (2003). My path leads to Tibet: The inspiring story of the blind woman who brought hope to the children of Tibet. New York, NY: Arcade.

Thomas, R. J. (2008). Crucibles of leadership: How to learn from experience to become a great leader. Boston, MA: Harvard Business Press.

Thomas, W., \& Znaniecki, F. (1918/1958). The Polish peasant in Europe and America. New York, NY: Dover.

Turner, J., \& Mavin, S. (2008). What can we learn from senior leader narratives? The strutting and fretting of becoming a leader. Leadership and Organization Development Journal, 29(4), 376-391.

Vaillant, G. E. (1995). Adapting to life (reprint edition). Cambridge, MA: Harvard Business School Press.

Vasterling, J. J., Daly, E. S., \& Friedman, M. J. (2011). Posttraumatic stress reactions over time: The battlefield, homecoming, and long-term course. In J. I. Ruzek, P. P. Schnurr, J. J. Vasterling, M. J. Friedman, J. I. Ruzek, P. P. Schnurr, ... M. J. Friedman (Eds.) , Caring for veterans with deployment-related stress disorders (pp. 35-55). Washington, DC: American Psychological Association.

Xenakis, S. N. (2014). Posttraumatic stress disorder: Beyond best practices. Psychoanalytic Psychology, 31(2), 236-244.

Yoeli, R., \& Berkovich, I. (2010). From personal ethos to organizational vision: Narratives of visionary educational leaders. Journal of Educational Administration, 48(4), 451-467.

Yip, J., \& Wilson, M. S. (2010). Learning from experience. In E. Van Velsor, C. D. McCauley, \& Ruderman, M. N. (Eds.). Handbook of Leadership Development ( $3^{\text {rd }}$ ed., pp. 63 -95). San Francisco, CA: Jossey-Bass. 


\section{Author Biographies}

Jenifer Wolf Williams, Ed.D., is a licensed professional counselor and independent researcher in Richardson, TX. Her practice focuses on trauma recovery, and she devotes several hours per week to mental health care for torture survivors, refugees, and asylum seekers in the Dallas area. Her research areas are trauma recovery and leadership.

Stuart Allen, Ph.D., is an associate professor in the Organizational Leadership Department at Robert Morris University as well as a dissertation chair for Ed.D. Organizational Leadership and D.Sc. Information Systems and Communications programs. He conducts research on leadership pedagogy, higher education, posttraumatic stress disorder, organizational culture, and teaching with technology. 